\title{
A Critical Discourse Analysis of Political Speech of Four Candidates of Rasht City Council Elections in 2013, with a view to Fairclough Approach
}

\author{
Mahshid Sadat Naghibzadeh Jalali \\ M.A Candidate of Applied Linguistics, Department of Foreign, Languages, \\ College of Humanities, \\ Takestan Branch, Islamic Azad \\ University, Takestan, Iran \\ Mnaghibzade2@gmail.com¹
}

Bahador Sadeghi

PhD of Applied Linguistics, Assistant Professor of Applied Linguistics, Department of Foreign Languages,

College of Humanities, Takestan Branch, Islamic Azad University, Takestan, Iran

\begin{abstract}
The current study is based on a Critical Discourse Analysis (CDA) approach of Rasht City Council Candidates' speeches, slogans, posters, and other campaign and propaganda tools used to take part in City Council Elections. Four candidates were selected in this study from whom two candidates were finally successful in the City Council Elections and the other two were not. All of four candidates had different academic education, working records, behavioral characteristics and thought tendencies. They filled a questionnaire prepared by the researcher containing their biographical information, purposes, motivations, kinds of political propaganda, organizational or other kinds of support, if any, and something else. Researcher also used a controlled interview asking some questions about the important factors influenced on the candidates' succession or fails including occupation, thought tendency, type of sloganeering, discourse techniques and so on. It should be noted that researcher considered some available sloganeering instruments like posters, CDs of lectures, pictures and slogans used by the candidates in Rasht City Council Election Process. Then the collected data were analyzed and compared to each other to identify the candidates' thoughts and ideas represented in their speeches. Based on Fairclough framework, this study investigates how the candidates try to justify their ideas and persuade their audiences by utilizing suitable ideological discourse structures in their speeches. Also the aim of this paper is to analyze and compare the candidates' speeches in order to discover the ideological strategies, power relations and persuasive techniques underlying their speeches and to identify the most important factors influenced on their success and fail.
\end{abstract}

Keywords: Discourse Analysis (DA), Critical Discourse Analysis (CDA), Political Discourse, Rasht City Council Elections

\section{INTRODUCTION:}

Discourse Analysis (DA) is regarded as a method to explain and analyze the results of any political elections. In fact discourse analysis techniques seem to be able to identify a general approach toward election and politics through considering some problems, issues and questions. Also the area of sloganeering and propaganda is treated as the area of discourse struggle. Based on this assumption, political parties who can give dominance to their discourse over others' discourse will succeed in political competition and any political party who fails in election campaign he/she will leave the election competition area.

This is discourse that enables us to identify each candidate's capabilities and insight in order to have the best choice in elections. In this direction, our understanding of politics and present conditions of our city and country is very important. So a dominant discourse is the one that can find the main problems and requirements of a society and submit a suitable response to them.Furthermore discourse analysis aims to show how changes in the use of language can be seen as a sign of general social and cultural changes in a society, which again have to do with changes in power relations. By doing so,

1 *Corresponding author. Tel.:+98 9125516329 
ISSN 2411-9563 (Print) ISSN 2312-8429 (Online)
European Journal of Social Sciences Education and Research
September-December 2014

Volume 1, Issue 2

critical discourse analysis (CDA) also has a special function in promoting interdisciplinary scientific work (Fairclough, 1992:72).Critical discourse analysis (CDA) is a branch for Discourse Analysis commonly used for analyzing political spoken and written texts. Fairclough (1995), a pioneer in modern CDA, defined it as:The kind of discourse analysis which aims to systematically explore often opaque relationships of causalityand determination between (a) discursive practices, events and texts, and (b) wider social and culturalstructures, relations and processes; to investigate how such practices, events and texts arise out of and areideologically shaped by relations of power and struggles over power; and to explore how the opacity of theserelationships between discourse and society is itself a factor securing power and hegemony.

The concept of hegemony was proposed by Antonio Gramsci (1971). In a Gramscian view, politics is seen as a struggle for hegemony. Hegemony emphasizes how power depends upon achieving consent and the importance of ideology in sustaining relations of power.

There is also a broader definition of CDA offered by Fairclough (1995) and Fowler (1996) saying that CDA treats discourse as a social practice and analyzes the influence of social, political and cultural contexts on discourse. Since CDA sees discourse as both produced and shaped by ideology, it stresses the essential linguistic characteristics of social relationship, social structures and the power distributed among them.

Critical Discourse Analysis (CDA) is used in different fields. However politics is regarded as the most important social fields in which CDA plays its valuable role that sometimes is called political - critical discourse analysis containing both political discourse and critical discourse. Based on contemporary approaches in CDA, political - critical discourse analysis deals with the reproduction of political power, power abuse or domination through political discourse, including various forms of resistance or counter-power against such forms of discursive dominance (Fairclough 1995; Van Dijk 1993).

In the book of Critical Discourse Analysis: The Critical Study of Language in 1995, Fairclough stated that language is connected to social realities and bring about social change. In the above-mentioned book he argues that government involves the manipulation and use of language in significant ways, and is particularly concerned with the linkage between Language, ideology and power relations within society. In "Language and Power", Fairclough distinguishes between power "in" and "behind" discourse. The former is concerned with discourse as a place where relations of power are actually exercised, for example power in "face-to-face" spoken language (as all of the candidates under this study confirmed it), power in cross-cultural discourse where participants are from different ethnic groupings and hidden power of discourse of the mass media. The latter (power behind discourse) states that how orders of discourse are shaped by relations of power. The term "Ideology" has several definitions out of which Fairclough chooses two: the first definition states that ideology is "any social policy which is in part or whole derived from social theory in a conscious way" and the Marxist definition according to which ideologies are, when struggle for political power is at issue, "ideas which arise from a given set of material interests" (Fairclough 2001a:77). Fairclough also (1995b) regarded the description of the formal features of text as an important element of CDA.

Van Leeuwen (1996) also offered several techniques that social actors can use in their speech such as: exclusion, inclusion, suppression, thematization, activation, passiviation, personalization, depersonalization, determination (including symbolization, reverseness and implicature) and indetermination, association and dissociation, differentiation and indifferentiation, beneficiation, backgrounding, abstraction, generalization, subjection. In this paper, these techniques have been used to analyze the candidates' speech and specially their slogans.

In Critical Analysis of candidates' speech, we can say that one of the most important factors for political candidates to be succeeded in any election campaign is the use of skillful language and their ability to persuade and impress their audiences. Discourse is not just a mental and lingual issue but it contains thoughts, emotions and excitements. The priority of a discourse is not necessarily rooted in reasoning power of that discourse but the priority of a discourse is a variable of mental and rational factors on one part and emotional, inductive and persuasive factors on the other part.

It is crucial to state that discourses are partial and positioned, and social difference is manifest in the diversity of discourses within particular cultural contexts. In this direction, the content of political propaganda is also very important in political election area. The more a political discourse is related to the general political culture of a society, the more the success percentage of that discourse will be. One important point in political-critical discourse analysis is that a successful political discourse is the one that moves toward the expected willingness and desires of a society. In Iran, for example, there are different cultural criteria that help a political discourse to be dominant in election campaigns, including: being management-oriented and program-oriented, having religious thoughts, fighting with immorality and corruption, bravery toward foreigners, willingness to stability and safeguarding the interests of the people, willingness to social and cultural 
freedoms, submitting effective strategies to have suitable interaction with others, simple-living and avoidance of luxury and so on.

Considering all above-mentioned explanations, this study is intended to use of Fairclough framework adopted from three important items of Language, Ideology and Power to analyze the results of Rasht City Council Election in 2013. This paper also uses of Fairclough approach to detect the candidates' discursive skills and structures and to discover how ideological strategies, persuasive techniques and power relations can help them to have a dominant discourse to attract the voters and to succeed in City Council Elections.

\section{LITERATURE REVIEW}

\subsection{Discourse analysis and its purposes:}

Fairclough (1995) defines a discourse analysis as an analysis method which includes linguistic description of the language text, interpretation of the relationship between the (productive and interpretative) discursive processes and the text, and explanation of the relationship between the discursive processes and the social processes. In addition, McCarthy (2000) states that discourse analysis is concerned with the study of the relationship between language and the contexts in which it is used. In other words, the focus of discourse analysis is not only on the pattern of language but it is also considering the context of text.

Shabanali Bahrampoor (2001) pointed out to the purposes of DA as follows:

- To clarify the relationship between author, reader and text

- To clarify deep structure of text production or discourse analysis process

- To identify the effect of text (general linguistic system) and context (social, historical, political, cultural, ...) on discourse

- To identify special conditions of discourse producer

- To show variability of meaning

- To manifest the relationship between text and ideology

- To create a new method and technique in studying text, media, politics and so on

There are some areas of DA such as speech act, pragmatics, conversation analysis, genre analysis, theories of politeness, indirectness, general discourse, discourse and cultures and critical discourse analysis. This study has used a critical discourse analysis in order to fulfill its purposes.

\subsection{Critical Discourse Analysis and its Emergence:}

The present study has used the method of Critical Discourse Analysis (henceforth CDA) for its purposes. CDA appeared in the 1980s as an approach toward the combination of language studies and social theory (Fairclough 1992) and it stems from a critical theory of language which sees the use of language as a form of social practice. CDA has been used in different subject areas. After publication of some important books such as Teun Van Dijk's Prejudice in Discourse (1984), Norman Fairclough'sLanguage and Power (1989), and Ruth Wodak's Language, power and Ideology (1989), CDA has emerged as a significant paradigm of research within linguistics.

Fairclough $(1989,1995)$, as a pioneer in modern CDA, identified his approach to a study of language as "critical language study" and proposed some approaches such as linguistics, sociolinguistics, pragmatics, cognitive psychology, artificial intelligence, conversation analysis and discourse analysis. It tells us how language can be represented from different point of view. It is a kind of relationship between or among ideas, power, language and the ordering of relationship within society.

Fairclough and Wodak (1997: 271-80) summarize the main tenets of CDA as follows:

- $\quad$ CDA addresses social problems

- Power relations are discursive

- Discourses constitutes society and culture

- Discourse does ideological work

- Discourse is historical

- The link between text and society is mediated 
- Discourse analysis is interpretative and explanatory

- Discourse is a form of social action.

CDA tells us why individuals say what they say; what is the intentions underlying their statements. In direction of handling these kinds of questions, another broad definition is offered by Fairclough (1995) and Fowler (1996) as follow: "CDA treats discourse as a social practice and analyses the influences of social, political and cultural contexts on discourse. Since CDA sees discourse as both produced and shaped by ideology, it stresses the essential linguistic characteristics of social relationships, social structures and the power distributed among them.

\subsection{Fairclough model for CDA}

Fairclough's $(1989,1995)$ model for CDA consists three inter-related processes of analysis which are related to three interrelated dimensions of discourse. These three dimensions are:

1. The object of analysis (including verbal, visual or verbal and visual texts).

2. The processes by means the object is produced and received (writing/ speaking/designing and reading/listening/viewing) by human subjects.

3. The socio-historical conditions which govern these processes.

According to Fairclough (as stated in Language and Power) each of these dimensions requires a different kind of analysis:

1. Text analysis (description): It is the stage which is concerned with formal properties of the text. In the case of description, analysis is generally thought of as a matter of identifying and 'labeling' formal features of a text in tenns of the categories of a descriptive framework.

2. Processing analysis (interpretation): is concerned with the relationship between text and interaction - with seeing the text as the product of a process of production, and as a resource in the process of interpretation.

3. Social analysis (explanation): is concerned with the relationship between interaction and social context - with the social determination of the processes of production and interpretation and their social effects.

Fairclough refers to what goes on at each of these stages as 'analysis', but it should be noted that the nature of 'analysis' changes as one shifts from stage to stage. In particular, analysis at the description stage differs from analysis at the interpretation and explanation stages. Also Fairclough argues that in order to interpret the features which are actually present in a text, it is necessary to make clear what other choice might have been made, and to discover the systems of options in the discourse types which actual features come from. Fairclough distinguishes between three types of value that formal features may have:

1. Experiential values: It is a trace of or a cue to the method in which the text producer's experience of the natural or social word is represented. It deals with content, knowledge and beliefs.

2. Relational value: It is a trace of or a cue to the social relationship which are enacted via the text in the context. It deals with social relation among people.

3. Expressive value: It is a trace of or a cue to the producer's evaluation of the bit of the reality it relates to. It deals with social identities.

4.

\subsection{Political discourse}

Politics is a social activity that can be defined, first and foremost, as a struggle for power, between those who are in power and those who are not but would like to be, although it can also be defined as a set of cooperation strategies carried out by some social institutions with a view to solving some social conflicts (Chilton 2004:3). Inherent properties of politics are a clash of interests, persuasion and manipulation, imposition of opinions as commonsensical, defining allies and opponents.

According to van Dijk, "discourse" refers to a description of all genres in politics or to politicians' discourses, so in politics "discourse" is "a socially constituted set of such genres, associated with a social domain or field" (van Dijk 1998:196). Political speech is a genre of political discourse and is part of public discourse. Also Fairclough (1995; Van Dijk 1993) 
ISSN 2411-9563 (Print) ISSN 2312-8429 (Online)
European Journal of Social Sciences Education and Research
September-December 2014

Volume 1, Issue 2

argued that political discourse analysis pays to reproduction of political power, power abuse or domination and it is based on various forms of discursive dominance.

\subsection{Power and ideology in critical discourse analysis:}

Ideology which manifests itself in all levels of society is a societal and national phenomenon. It goes beyond our habitus, extending to power struggles in society (Fairclough, 1989). Ideology also can be defined as systematic ideas or ideals which form a base for economic or political theory. Ideologies have a role in legalization of power abuse by dominant group.

In politics, different ideologies struggle together for dominance. In this area language forms related to oral and written political text can signal the power by discovering the specific ideology embedded in them. Also power is signaled by a politician control of a social and political occasion by using of specific genres.

In " Language and Power" Fairclough argued that power and ideologies are not linked to particular groups of people or linguistic forms or permanent attribute of a person or social group but ideology is linked to discourse and other moments of social practices. He also emphasized that orders of discourse vary in different social cultures. In this process all social orders of discourse are put together as a hidden effect of power. Languages provide a fine vehicle for differences of power in hierarchical social structures, because different ideologies struggle for dominance. There are several factors which are important in power in language. Power signaled not only by grammatical form within an oral or written text but also by a person control of a social or political occasion by using of the text genres. Fairclough has emphasized that power can be exercised through physical violence and through the manufacture of consent, whereby those who have power can exercise it and keep it by coercing others to go along with them (Fairclough, 2001b, pp. 27-28). Fairclough has been very interested in the role of language in producing, maintaining and transforming unequal power relations and no doubt this has influenced on his perspective.

\subsection{Van Leeuwen techniques}

Van Leeuwen (1996) offered several techniques to be used by social actors as follows: Inclusion and Exclusion deals with incorporating and deleting the social agents intentionally or unintentionally. Suppression means making hidden. It also means excluding both social actors and their activities so that no trace is left in the representation. Backgrounding is a kind of exclusion that leaves traces in the representation. It means that something is deleted in a specific activity but its effect or trace is manifested in other part of the clause. Thematization deals with paying more attention to a word or phrase. In Activation social actors are presented as active and dynamic forces in an activity. InPassivization social actors are presented as undergoing an activity. Personalization and depersonalization: the former occurs where something inanimate takes the characteristics of human being and in the latter human being takes characteristics of inanimate things. Determination: it occurs when the character of social agent is clear but in indetermination this character is vague and unspecified. In Determination social agent may be one person or consisted of several individuals. The former itself is from three types including a) Reverseness in which social actor has two different and reversal roles, b) symbolization in which an ideal and symbolized agent is replaced by a social agent, c) implicature is an inference meaning created at the result of floating one or more conversational maxims of Grice. Association means two or more social actors associate to each other to perform a social activity and we use of "," among the agents but in dissociation two or more social actors are participated in a social activity and we use of "or" among the agents. It means that the social activity can be done by each of them not all of them. Differentiation and indifferentiation: differentiation is a kind of separation between two social agents, social activities or social conditions (such as separation between rich and poor people). In Beneficiation the social agent benefits from a social act. Beneficialization may also be realized by participation. In this case beneficialized agent is recipient or client in relation to a material process or receiver in relation to a verbal process. In Abstraction a special characteristic is abstracted from a group of people and it refers to the members of that group. Generalization and specification: in the former social actors can be represented as classes but in the latter social actors can be represented as specific identifiable individuals.

\section{OBJECTIVES OF THE STUDY:}

With a view to Faircough's framework, this paper intends to analyze, compare and contrast the Rasht City Council candidates' speeches, slogans, posters, trackers and interviews for City Council Election in 2013 in order to find out how 
the candidates try to persuade and justify their audiences to be succeeded in elections. In general the purpose of this study is summarized in two parts as follows:

- To detect the candidates' discursive structures, persuasive techniques and power relations based on Fairclough approach in order to have a dominant and justifiable discourse to attract the voters and to succeed in City Council Elections.

- To identify the ideology underlying each candidate's speech and slogans.

\section{METHODOLOGY}

\subsection{Participants:}

Four candidates were selected accidently in order to meet the purpose of this study, from among them two candidates (Mr. A and Mrs. Sh') were selected from City Council Office in Rasht", Iran who were succeeded in the Elections on 2013, and the other two Candidates (Mr. D and Mr. R) - who experienced a fail in the Elections - were introduced by one of themembers of Rasht City Council Office.

\subsection{Data source}

The data used in this study included a questionnaire (attached in appendix), oral interviews, trackers, posters having different figures and slogans, CDs of the candidates' propaganda and some written interviews in publications.

\subsection{Analytical framework}

The framework used in this study was that of Fairclough's $(1989,1995)$. Fairclough emphasized on discourse structures and formal features of oral and written text in order to have an effective interpretation. He also stressed on the use of language in significant ways, and his framework is particularly concerned with the linkage between Language, ideology and power relations in order to have a dominant speech.

This study also used Van Leeuwen social actors' techniques (1996) - all of them described in literature review - to analyze the candidates' statements and specially their slogans.

\section{SAMPLE ANALYSIS}

\section{Statements of Mrs. Sh. as the candidate succeeded in Elections:}

In general, my main reason to attend in City Council Elections was my serious willingness to serve the civilized people of Rasht city. This is my belief that city councils are not places to do political activities; instead, city council should have efficient plans to manage the city, to provide comfort and security for people and to promote the city's growth and development proportionate to the spread changes of the country and of the world. In my weekly publication [Guilan Child (Farzandane Gil)], I pointed to some propositional plans to improve the city management as follow: 1 . to create conditions to participate people in city programming, 2. to increase official health and to create a customer-oriented system in municipalities, 3 . to revise municipality's income system, 4 . to construct the sport, cultural and amusement places in the city. Another reason that persuades me to attend in Elections was the weak presence of women in city councils area. I emphasized that we, women, can reinforce the woman's management role through our active presence in the field of civil management areas. I had no slogan, no special propaganda or political meetings and no protection by any political parties. I had only some posters with a single figure and I submitted my plans and propositions in my weekly publication for the audiences. The most important factors influenced on my success are as follows: to trust in God, protection of my family members and my presence in national media of Guilan Center (both in radio and television) for 23 years. Media helped me to be an introduced character among Rasht people. Also I stress the need to observe the codes of Islamic government.

\footnotetext{
${ }^{1}\left[{ }^{*}\right]$ Because of observing confidentiality, the use of the candidates' full name is avoided. [ $\left.{ }^{*}\right]$ I'd like to thank all members of Rasht City Council Office and the candidates who help for this research reported here.
} 


\subsection{CDA of Mrs. Sh text}

Mrs. Sh. - who is the editor-in-chief of a weekly publication (Farzandane Gil) - used media discourse as a part of her campaign propaganda in City Council Election time so the nature of power relation enacted in her discourse is not completely clear; in this respect, Mrs. Sh.' discourse involves hidden relation of power as Fairclough called it "power behind discourse". Media discourse is a kind of one-sidedness discourse in which candidate doesn't know who is among the audiences and what they say is addressed to ideal subject.

Different candidates have different kinds of strategies for problem solving. Through detailed describing of a long list of her plans and programs in her weekly publication, Mrs. Sh. tries to show how much problems exist in Rasht City and how she tries to resolve them; by this persuasive strategy, she stimulates the sense of hope in audience. In respect to the women's role she emphasized on more active presence of women in city management in order to strengthen the position of women in their social and public life. By using of the words "emphasize" and "point out" she shows a type of power in her statement. Another characteristic of Mrs. Sh.' statements is that she used Van Leeuwenpersonification technique saying "media helped me..." that is a compensatory tendency to give impression o teaching each of the people handled in mass as an individual.

In her final statement, Mrs. Sh. used the phrase "Islamic Government". Although she never speaks about her political tendency, this phrase is the nodal point of Principalists party in our country; he also used the word "stress" in this sentence that can be good indicators of ideologies underlying her speech. The subject position of Mrs. Sh. is a female so she used of another strategy to claim solidarity with women and articulate their desire, hope and wills. She applied a relational value by using pronoun "we". Cultural values were also influenced in her success. She received a lot of votes because of her justifiable appearance, firm character and religious thoughts indicating the social identity of the woman political candidate in Islamic country.

\section{Statements of $\mathrm{Mr}$ A. as the candidate succeeded in Elections:}

My main purposes to attend in Rasht City Council Elections are divided in two parts: internal motivation involves my inner apprehensions arising from the problems of management policy that I saw in my city; external purposes involve the problems of Rasht people that persuade me to work as a useful servitor for my city's people; and I think that all of us should manipulate our all efforts to resolve our city's problems. The crucial factors influenced on my success are to trust in God, protection of my family members, my good working records, propaganda such as posters and interviews in publications, but I have to emphasize that the most effective factor was my presence in the most areas of the city and having face to face speech with people, receiving their comments and propositions and submitting my plans and strategies to resolve the current management problems of the city; and finally I requested people for helping me to solve the all mentioned problems. Students, youth and common people cast the most amounts of votes for me. On the subject of women role I have to say that women were my first working group; I believe that women are able to act in some fields better than men and I ' $m$ not agree with any limitation for women in any social activity. During Elections, I had a policy saying that "we do our work and we pay no attention to others"; but in fact, in social, electoral and political processes, you cannot do your work separately through ignorance of political parties, political events and competitors, so a candidate have to observe moderation and to handle the type of his/her political interaction with parties, competitors and influenced individuals.

Slogan: 1. We need no young consulters, we need young managers. 2. Efficient management, Active citizen, an Advanced city.

\subsection{CDA of Mr. A. text}

At the beginning of his speech, Mr. A introduced himself as a servitor of people. By this technical register, he used two techniques simultaneously; one of them is persuasive technique because he uses emotive language to create a sense of consensus in audiences, and the other technique is using of relational value because of politeness in his language. Also through describing his plans, he used persuasive strategy of problem resolution combining relational elements of conversational discourse. When he says "all of us", he expresses solidarity with relational elements of a more traditional political discourse type and when he uses of modal verb "should" he shows authority in his speech, so we can also see a sign of power relation in this statement.

Mr. A frequently used face-to-face discourse during his campaign propaganda in City Council Election and he declared that it was the most effective measure in his succession. In face-to-face discourse he designed his 
contributions for the particular people he was interacting with. He knew who his audiences were, so he tried to adapt the language heused and to decide to keep this adapting based on the feedback he got from his audiences. The most characteristic of face-to-face discourse is that the nature of power relation enacted in it is often clear. In his tracker, Mr. A named several responsibilities undertaken in several companies. Fairclough believes that statement of responsibilities is another sign of power relation in politicians' discourse. He also requested people for helping him. In "Language and Power", Fairclough believes that there is a close relationship between request and power.

Concerning the women's role, Mr. A. emphasized on his objection forany limitation of woman' political and social activity. The strategy existed in this statement is using of disagreement. According to Fairclough, candidates use disagreement in their speech in order to exercise influence and power. Also in the mentioned sentence, an experiential value is usedbecause of being negative (I don't agree with any limitation ...). Negation is the basic way to distinguish what is not the case in reality from what is the case. In final part of his speech, Mr. A. encouraged political candidates to have a moderate interaction with political parties and influenced individuals. Through analysis of this sentence, we can detect some ideological strategies. Although he never speaks about his political tendency, it seems that his thoughts are close to Reformist party because moderation and political interaction are from the moments of Reformists. Also in his slogan he said "we want young manager". By this sentence he used another persuasive technique introducing himself as a capable manager to persuade the audiences.

\section{Statements of Mr. D. who failed in Elections:}

I lived in Rasht city for many years having different responsibilities and I wished I make my city so beautiful and pleasant with Islamic architecture that people have more comfort and enjoy from living in their city. I was sure that my management records in security, disciplinary and transportation could help me to meet these purposes. From among different types of propaganda I selected these items: being among dear people of Rasht to have an honest speech with them, presence in mosques and social meetings and printing some posters. I failed in City Council Elections but I have to say that my intense tendency towards jurisprudent leadership (VelayateFaghih) and our country's system was from effective reasons to receive the clean vote.

Slogan: Yesterday's sacrifice, Today's management, Tomorrow's development

\subsection{CDA of Mr. D text}

All candidates contribute to the emergence of a new hegemonic discourse in their political discourse. Referring to his presence in the War imposed by Iraq and to risk his life for defending our country, Mr. D. used of a persuasive strategy to stimulate people's sense of sympathy. He also pointed to all of his responsibilities in security, disciplinary and transportation areas. This statement of responsibility is another sign of power relation. Mr. D. also believes in the effect of face-to-face discourse with people during the Election campaign that is also other sign of power.There are some ideological strategies beneath Mr. D.' statements, for example sing of some words such as "Islamic architecture" and "presence in mosques" are indicator of his religious thoughts; he also said that his tendency towards "Velayat" is resulted in receiving clean votes by him. By using of the word "Velayat", he clearly introduced himself as a proponent of Principalists because "Velayat" is nodal point of Principal party in Iran. Also the phrase "clean vote" has an expressive value. Also using of the phrase "dear people of Rasht" shows a kind of politeness in his discourse and has relational value based on Fairclough framework.

Mr. D. had a single slogan in which we can see Van Leeuwen'sdetermination technique.This technique has several types. One of them is reverseness that is used in this slogan. It means that social actor has reversal roles. Also multitemporal reverseness is used in the slogan. We have three times of yesterday, today and tomorrow.

\section{Statements of Mr. R. who failed in Elections:}

Concerning my motivation to attend in City Council Elections, I can point to my sense of personal duty, willingness to try for constitutive changing, development and public welfare, absorbing the certain capitals and promotion of tourism industry, and finally developing the qualitative and quantitative level of amusement places. I think that all of us can play our role based on our capabilities and specialties to create a developed city. I failed in Elections but I believe that the most important factors to be succeeded in any Elections is spending much money and 
performing efficient campaign propaganda. I received my votes by youth and athletes; I seriously stress that I had no affiliation to any party including principalists or reformists. In respect to women's role I can say that they can act even better than men in some social fields; and my final speech is that in order to succeed in any elections spending enough money and performing massive propaganda are from the most effective items.

Slogan: Truthfulness, Management, Developed city

\subsection{CDA of Mr. R. text}

At the beginning of his speech, Mr. R. described his attendance in City Council Election as a "personal duty" for developing the city. This phrase has an expressive value. But the main point of Mr. R. is that he seriously declared that he is not affiliated to any political parties. He separated himself from both Principalists and Reformists. By using of "seriously declare" he somehow shows a power in his speech. In another sentence, he showed that he has some capabilities and background knowledge in business and absorbing the certain capitals and acted as a unifying factor that want to work with people to meet their common goals. He used of the phrase "all of us"; this is deictic technique that candidates use in order to create a close relationship with the audiences; this is also persuasive technique. Also in political speech, when a candidate uses the phrases such as "we", "all of us" and like these, he/she serves corporate ideologies which stress the unity and solidarity of a people. Also when electoral candidates use the expressions indicating solidarity, they really speak about relational value. He used also experiential value when he emphasized he had no affiliation to any party (negative sentence). As other candidates, Mr. R. prepares a long list of his responsibilities and his plans and purposes in his trackers all of which have the theme of power relation.

Mr. R.' slogan involves three words. Truthfulness, management, a developed city, by all of which he tried to use of persuasive techniques to justify the audience.

\section{CONCLUSION}

In direction of making this paper, CDA has been a useful instrument to analysis, to compare and to contrast of political speeches of Rasht City Council Candidates, because it helped to realize the interdependency of language and ideology; ideology and socio-cultural practice; and socio-cultural policies. CDA also made possible to excavate meaning from the candidates' utterances enabling more accurate interpretations of their statements. Also the content of each candidate's speech was analyzed based on Faircloughian pattern to discover their hidden ideologies, power relation, persuasive technique and formal features manifest in their interviews, slogans, posters, questionnaire, trackers and other propaganda items. The main axis and content related to the candidates' campaign propaganda were excavated based on their repetition and emphasis and their strategic slogans.

In this study the theme of power was achieved through the manipulation of technical registers, imperative sentences to invite people to make an ideal city, statement of responsibility of people and themselves, modal verb (such as should), urges, stresses and statement of disagreement. Also we saw that how different candidates tried to impose upon the context for their strategic purposes. They produced various types of problem resolution integrating with the use of relational values which indicated unity or solidarity (such as: we, all of us ...) and authority (such as speaking on behalf of people).

Undoubtedly, there were some similarities in the speeches of candidates as regards the formal features and linguistic elements used to explain their ideological beliefs. Three of them stressed the effect of face-to-face discourse in electoral discourse. The main point that I want to make is that although in society such as Iran - where power relationships are clear and stable - we cannot expect to find a great deal of ideological diversity, there is also some degree of ideological difference so that ideological uniformity is never completely achieved.

In general, the result of this study showed that, CDA can be regarded as a valuable opportunity to identify all hidden realities such as power, ideological strategy, persuasive technique and linguistic device underlying a politician discourse which has been naturalized. 


\section{REFERENCES}

[1] Fairclough, N. (1989). Language and Power: Published in the United States of America. By Longman Inc., New York.

[2] Complete Citation: Henderson, R. (2005). A Faircloughian approach to CDA: principled eclecticism or a method searching for a theory? Melbourne Studies in Education, 46 (2), 9-24.ISSN 0076-6275.

[3] Accessed from USQ ePrintshttp://eprints.usq.edu.au

[4] Fairclough, N. (1999). Global Capitalism and Critical Awareness of Language.Department of Linguistics and Modern English Language, Lancaster University, LA1 4SE.

[5] Fairclough, N. (1995). Critical Discourse Analysis-The Critical Study of Language. London: Longman.

[6] Fairclough, N., Notes for Norman Fairclough'sAnalysing Discourse: Ch 4 (V3) Genres \& Generic Structure.

[7] Fairclough, N. Analysing Discourse: Textual analysis for social research. London and New York.

[8] BĂRBULET, G. (1918). Discourse Analysis with Michel Foucault \& Critical DiscourseAnalysis with Norman Fairclough. Universitatea, Alba Iulia.

[9] Hashemi, M. R., \&Ghanizadeh, A. (2012). Critical discourse analysis and critical thinking: An experimental study in an EFL context.

[10] Available online at www.sciencedirect.com

[11] Janks, H. (1996).Critical Discourse Analysis as a Research Tool.University of the Witwatersrand, Johannesburg, South Africa.

[12] BHATIA, A. (2006). Discourse \& Society: Critical discourse analysis of political press conference. Vol17(2): 173-203,10.1177/0957926506058057. The online version of this article can be found at: http://das.sagepub.com/content/17/2/173.

[13] Mc Carthy, M. (2000). Discourse Analysis for Language Teachers. Cambridge: Cambridge University Press.

[14] Matić, D. (2012). IDIOLOGICAL DISCOURSE STRUCTURES IN POLITICAL SPEECH: Original Scientific paper. Komunikacijaikultura online, Godina III, broj 3.

[15] Viberg, B. (2011). In the name of freedom: A Critical Discourse Analysis of the Political Discourse in the Inaugural Speeches of George W. Bush and Barack H. Obama from a post-colonial perspective: English Linguistic Essay. EN1C03 V11.

[16] Brokensha, S. (2011). NOTICING US AND THEM CONSTRUCTIONS: THE PEDAGOGICAL IMPICATIONS OF A CRITICAL DISCOURSE ANALYSIS OF REFERRING IN POLITICAL DISCOURSE. Per Linguam 2011 27(1):56-73. http://dx.doi.org/10.5785/27-1-98.

[17] Rashidi, N.\&Souzandehfar, M. (2010).A CRITICAL DISCOURSE ANALYSIS OF THE DEBATES BETWEEN REPUBLICANS AND DEMOCRATS OVER THE CONTINUATION OF WAR IN IRAQ.

[18] Van Dijk, Teun A., What is Political Discourse Analysis. Universiteit van Amsterdam.

[19] Ainsworth, S., Discourse Analysis as Social Construction: Towards Greater Integration of Approaches and Methods. The University of Melbourne, Parkville Victoria 3010 AUSTRALIA.

[20] Weisberg, M., Three Kinds of Idealization: supported by National Science Foundation grant SES-0620887. University of Pennsylvania.

[21] Rahimi, F.\&Riasati, m. j. (2011). Critical Discourse Analysis: Scrutinizing Ideologically-Driven Discourses. Critical Discourse Analysis: Scrutinizing Ideologically-Driven Discourses, Vol. 1 No. 16. 
[22] Sahragard, R.\&Davatgarzadeh, G. (2010). The Representation of Social Actors In Interchange Third Edition Series: A Critical Discourse Analysis. The Journal of Teaching Language Skills (JTLS), Vol. 2, No. 1, Ser. $59 / 4$.

[23] Soltani, S. A. A. (2004). Discourse Analysis as a Theory and Method

[24] Bahrampour, Sh. (2000). "Introduction to Discourse Analysis", Discourse and Discourse Analysis, Tehran: Discourse Culture

[25] Tajik, M., \&Roozkhosh, M. (2008).Consideration of the $9^{\text {th }}$ period of Iranian Presidential Election. Literature and human sciences faculty journal, No.61

\section{APPENDIXES}

The questionnaire submitted to four candidates of Rasht City Council Elections:

\section{Questionnaire}

1. Personal information:

Full name: ........................... Age

Sex:

Male.

Female

Education:

Field of study:

2. Please explain about your purposes and motivation to take part in City Council Elwctions?

3. What slogans you have used in City Council Election?

4. What kinds of sloganeering or propaganda you have used to be succeeded in City Council Election?

5. Please explain about the most important factors influenced on your succession (in case of succession)? e.g. occupation, being handsome, beauty, thought tendency, type of your sloganeering and so on?

6. Have you been received any financial or other kinds of supports by anybody or any organization? How?

7. How do you evaluate women and their management role in society?

8. Which group of people cast the most amounts of votes for you? (e.g. adolescences, students, athletes, market men, common people and so on)

9. Explain about the role of propaganda, picture and posters in your succession?

10. In case of fail, what are your recommendations to be succeeded in a future election? 